\title{
Development of thermal and structural design technology for a hermetically sealed oil transformer
}

\author{
S. Lee ${ }^{1}$, J. Y. Lee ${ }^{1}$, J. C. Yun ${ }^{1}$, J. Y. Park ${ }^{1} \&$ J. H. Woo ${ }^{2}$ \\ ${ }^{1}$ Electro-Mechanical Research Institute, \\ Hyundai Heavy Industries Co. Ltd., South Korea \\ ${ }^{2}$ Transformer Development Department, \\ Hyundai Heavy Industries Co. Ltd., South Korea
}

\begin{abstract}
The hermetically sealed oil transformer is designed by applying the expanding function of the tank due to the volume change of the insulation oil according to the temperature rise. When insulation oil expands, increase in the volume of corrugated-fin prevents pressure rise of the transformer. The purpose of this study is to analyze the thermal and structural stability of the transformer to deal with the pressure variation due to the temperature change. For the wind turbine transformer, the vegetable oil transformer has advantages of excellent biodegradation and fire-resistant properties, such as an exceptionally high fire point. Therefore, the design technology of the transformer to deal with the pressure variation has been investigated by fluid structure interaction simulations. The amount of expanded oil inside the corrugated-fin has been estimated for operating load cases, and the design of the corrugated-fin to control the variations of the inside oil pressure has been proposed. Additionally, the structural integrity of a hermetically sealed transformer has been evaluated by both numerical and experimental methods. Hydraulic and thermal tests for the transformer have been performed, and measured values are compared with the analyses results.

Keywords: hermetically sealed transformer, vegetable oil, corrugated-fin, oil expansion calculation.
\end{abstract}




\section{Introduction}

Hermetically sealed oil transformers whose insulating liquid is protected against the effects of the atmosphere have advantages of little or no maintenance to keep the quality of the insulating materials [1]. Since a conservator is not required for a hermetically sealed design, this type of transformer has additional advantages arising from the reduced overall height in the case of installing at the wind turbine [2]. The hermetically sealed oil transformer is designed by applying the expanding function of the tank due to the volume change of the insulation oil according to the temperature rise. When insulation oil expands, increase in the volume of corrugated-fin prevents pressure rise of the transformer. Without the conservator, oil temperature variation leads to expansion and contraction of the transformer tank and this affects the transformer tank design, behavior and aging.

Additionally, the demand for a vegetable oil-filled transformer has recently increased in the world because of the need for eco-friendly electric power equipment [3]. For the wind turbine transformer, the vegetable oil transformer has advantages of excellent biodegradation and fire-resistant properties like exceptionally high fire point [4].

In this paper, the design technology of the vegetable oil transformer to deal with the pressure variation due to the temperature change is investigated by fluid structure interaction simulations. Heat and flow analyses have been conducted to predict temperature rise in an oil-filled transformer and the amount of expanded oil has been estimated for different load cases. The structural integrity of a hermetically sealed transformer is evaluated by both numerical and experimental methods. Hydraulic and thermal tests for the transformer are performed, and measured values are compared with the analyses results.

\section{Fluid-structure interaction analysis}

\subsection{Thermal analysis}

The main heat transfer mechanism inside the tank is natural convection. In the natural convection, temperature and density gradients are produced by the heat transfer. The fluid motion in the natural convection is a result of buoyancy forces arising from temperature and density variations within the fluid. In order to find out the temperature distribution at the corrugated-fin and tank, the twodimensional numerical analyses using a commercial flow analysis solver, Fluent have been conducted.

In the analysis, the heat sources are defined separately as shown in fig. 1. For the natural convective heat transfer, equations of motion, continuity equation and energy equation are discretized altogether, and are solved numerically. Figure 1 shows the hermetically sealed wind turbine transformer which composed of tank, corrugated-fin and active part. The active part is a heat source part and made up of a core part and winding part. The hermetically sealed transformer is of flexible design so that it can accommodate the volume changes of the liquid in response to temperature without suffering damage. The flexible elements are the 
individual corrugations of the corrugated tank widely used for distribution transformers. The corrugations bulge outwards when the pressure rises and contract again as it falls. Since a conservator is not required for the hermetically sealed design, this type of transformer has additional advantages arising from the reduced overall height.

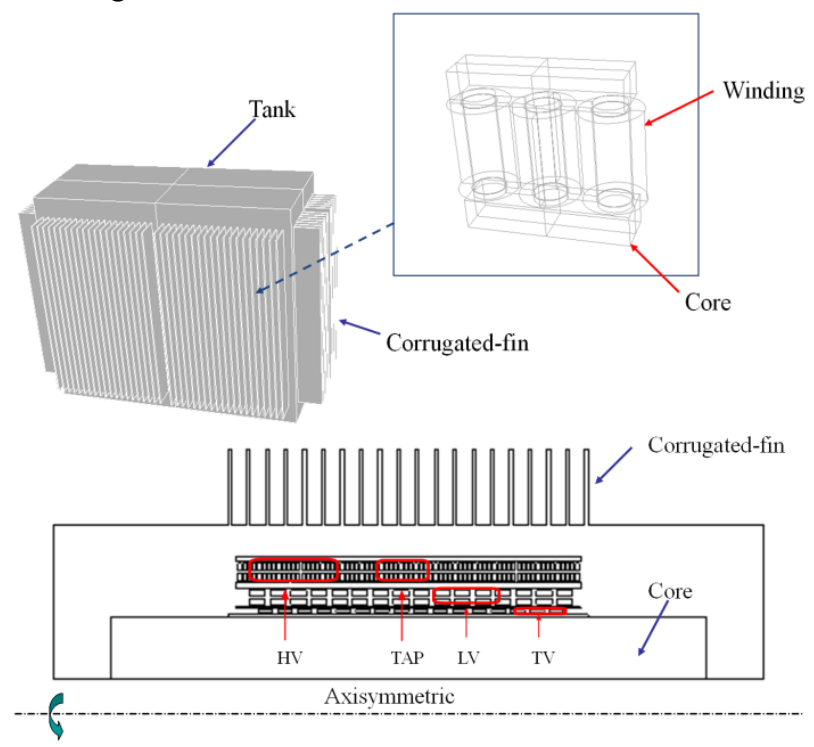

Figure 1: Schematic diagram of the hermetically sealed transformer with corrugated-fin.

The analysis model is a hermetically sealed transformer for the wind turbine. The transformer tank size is $2,300 \mathrm{~mm} \times 1,100 \mathrm{~mm} \times 2,160 \mathrm{~mm}$. The transformer has 108 ribs and the dimension of ribs is $1,400 \mathrm{~mm} \times 190 \mathrm{~mm}$. The heat generation at the active part, core and winding is realized in the numerical model. The flow analysis is done for laminar flow since there is no inlet and outlet boundary condition. Therefore, boundary layer mesh is applied to simulate natural convection precisely. The tank and the corrugated-fins are designed with the thickness of $9 \mathrm{~mm}$ and $1.4 \mathrm{~mm}$ steel plates, respectively. $1 / 4$ symmetric model was applied to obtain more accurate analysis result.

One of the most important requirements for high operational reliability and long life of liquid-filled transformers is that the electrical and mechanical properties of the insulation materials be maintained at a high level for years on end. These materials are mainly transformer oil and solid materials with a cellulose base. Vegetable insulation oil is an alternative to the mineral oil coolant commonly used in the power transformers. Vegetable oil has preferable environmental properties compared to mineral oil, most notably rapid and complete biodegradation. They qualify as "K" class per IEC 61100 and have a fire point of $360^{\circ} \mathrm{C}$, less-flammable [5]. The differences in chemical composition are manifested in differences in fluid properties. Table 1 shows insulation oil 
Table 1: $\quad$ Material properties of the wind turbine transformer oil.

\begin{tabular}{|c|c|c|c|c|c|}
\hline \multirow{2}{*}{\multicolumn{2}{|c|}{ Material properties }} & \multirow{2}{*}{ Mineral oil } & \multicolumn{2}{|c|}{ Vegetable oil } & \multirow{2}{*}{$\begin{array}{l}\text { Silicone oil } \\
\text { (DC 561) }\end{array}$} \\
\hline & & & Midel 7131 & FR3 & \\
\hline \multicolumn{2}{|c|}{ Density $\left[\mathrm{kg} / \mathrm{m}^{3}\right]$} & 850 & 970 & 920 & 960 \\
\hline \multirow{3}{*}{$\begin{array}{c}\text { Kinematic } \\
\text { viscosity } \\
{[\mathrm{cSt}]}\end{array}$} & $100^{\circ} \mathrm{C}$ & 2.87 & 5.25 & 8 & 16 \\
\hline & $40^{\circ} \mathrm{C}$ & 11.2 & 28 & 34 & 38 \\
\hline & $0^{\circ} \mathrm{C}$ & 63.5 & 240 & 184 & 95 \\
\hline \multicolumn{2}{|c|}{$\begin{array}{c}\text { Thermal conductivity } \\
{[\mathrm{W} / \mathrm{m}-\mathrm{K}]}\end{array}$} & 0.120 & 0.144 & 0.168 & 0.151 \\
\hline \multicolumn{2}{|c|}{ Specific heat [cal/gm-K] } & 0.46 & 0.45 & 0.45 & 0.36 \\
\hline \multicolumn{2}{|c|}{$\begin{array}{c}\text { Thermal expansion } \\
\text { coefficient }[1 / \mathrm{K}]\end{array}$} & $7.3 \times 10^{-4}$ & $7.5 \times 10^{-4}$ & $7.4 \times 10^{-4}$ & $1.04 \times 10^{-4}$ \\
\hline
\end{tabular}

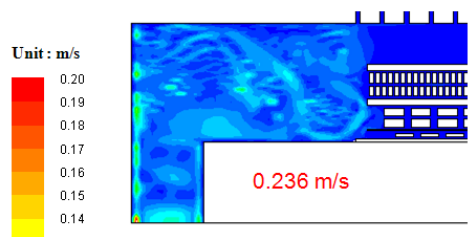

(a) Mineral Oil

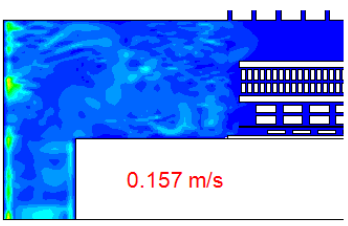

(b) Vegetable Oil (Midel)

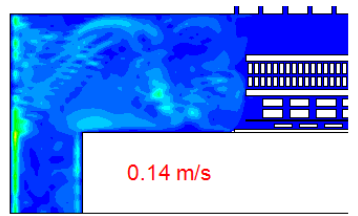

(c) Silicone Oil (DC561)

Figure 2: Velocity distribution of the rated operating condition.

properties used in the wind turbine transformers according to the temperature variation $[6,7]$.

Vegetable oil has advantages over mineral oil in terms of fire safety, environmental risk, and thermal performance. These high fire point fluids are self-extinguishing (non-propagating). The thermal characteristics and interactions with cellulose insulation give longer insulation life or allow higher or extended overloads without abnormal loss of insulation life. However, the viscosity of vegetable oil is slightly higher than mineral oil. To compensate thermal properties, transformer cooling design should be considered along with the thermal expansion, thermal conductivity, and heat capacity.

Since the material properties of the insulation oil differ noticeably, numerical heat transfer analyses have been conducted to verify the thermal stability of the vegetable insulation oil transformer and compare cooling performance. Even though the vegetable oil has many advantages, it has limitations with low cooling 
performance due to having three times higher viscosity than mineral oil. Figure 2 shows the velocity contours of the hermetically sealed transformer. Because of the augmentation of pressure drop resulting from the variation of physical characteristics, internal oil circulation decreases and maximum winding temperature rises. Figure 3 shows the temperature contours of the windings. The simulation results of three kinds of insulation oil are summarized in table 2 . As seen from table 2, the maximum temperature rise value of the vegetable oil is about $5 \mathrm{~K}$ higher than that of mineral oil. On the basis of these results we can suggest a cooling design of a hermetically sealed vegetable oil transformer.

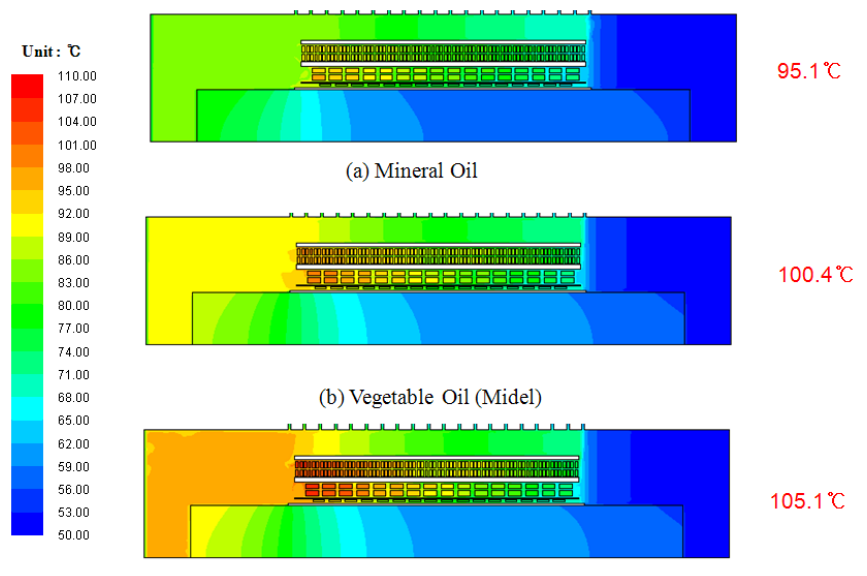

(c) Silicone Oil (DC561) Ambient Temperature: $50^{\circ} \mathrm{C}$

Figure 3: Temperature distribution of the rated operating condition.

Table 2: $\quad$ Temperature results of the rated operating condition.

\begin{tabular}{|c|c|c|c|c|c|c|}
\hline \multirow{2}{*}{} & \multicolumn{2}{|c|}{ Mineral oil } & \multicolumn{2}{c|}{ Vegetable oil (Midel) } & \multicolumn{2}{c|}{ Silicone oil (DC 561) } \\
\cline { 2 - 7 } & $\begin{array}{c}\text { Max. } \\
\text { temp. }\end{array}$ & $\begin{array}{c}\text { Avg. } \\
\text { temp. }\end{array}$ & $\begin{array}{c}\text { Max. } \\
\text { temp. }\end{array}$ & $\begin{array}{c}\text { Avg. } \\
\text { temp. }\end{array}$ & $\begin{array}{c}\text { Max. } \\
\text { temp. }\end{array}$ & $\begin{array}{c}\text { Avg. } \\
\text { temp. }\end{array}$ \\
\hline TV & 35.06 & 25.35 & 40.89 & 28.73 & 44.46 & 30.04 \\
\hline LV & 45.06 & 27.47 & 50.40 & 31.61 & 55.01 & 33.87 \\
\hline HV & 41.72 & 29.03 & 48.40 & 34.02 & 54.61 & 36.94 \\
\hline TAP & 31.60 & 30.96 & 37.16 & 36.16 & 40.21 & 38.85 \\
\hline Core & 29.61 & 12.19 & 37.99 & 16.02 & 41.02 & 16.56 \\
\hline Fin & - & 7.75 & - & 6.82 & - & 6.07 \\
\hline Oil & - & 19.76 & - & 22.70 & - & 24.32 \\
\hline
\end{tabular}

[Unit: K] 


\subsection{Calculation of oil expansion in the hermetically sealed transformer}

Now, we can estimate approximately increasing of oil volume due to temperature rise. Regarding the relationship between oil density and its volume, oil expansion can be calculated as follow [8]:

$$
\Delta P=\frac{30 E T^{3} \Delta V}{N L W^{5}} \quad \Delta V=\frac{m_{0}}{\rho_{0}\left(\theta_{T O}\right)_{2}}-\frac{m_{0}}{\rho_{0}\left(\theta_{T O}\right)_{1}}
$$

where,

E: Young's modulus

$T$ : Thickness of tank

$N$ : Number of ribs

$L$ : Length of corrugated-fin

$W$ : Width of corrugated-fin.

So, by knowing the oil temperature increase and resulting oil volume, we can calculate oil pressure deviations in the transformer. Table 3 shows various design calculations of the HHI wind turbine transformer. To meet the design criteria, various parameters such as operating condition, corrugated-fin length and width, number of ribs and oil density are considered. As seen in (1), increasing the number of ribs can decrease the rise of oil pressure. Also, a larger dimension of ribs, especially width of ribs, causes lower pressure increase and mechanical stresses.

Table 3: Calculation of vegetable oil expansion in hermetically sealed transformer.

\begin{tabular}{|c|c|c|c|c|}
\hline Condition & $\begin{array}{c}m_{o} \\
{[\mathrm{~kg}]}\end{array}$ & $\begin{array}{c}\Delta T \\
{[\mathrm{~K}]}\end{array}$ & $\begin{array}{c}\Delta V \\
{\left[\mathrm{~m}^{3}\right]}\end{array}$ & $\begin{array}{c}\Delta P \\
{[\mathrm{bar}]}\end{array}$ \\
\hline $\begin{array}{c}1^{\text {st }} \text { Design model } \\
- \text { Midel }\end{array}$ & 1,546 & 50.4 & 0.0588 & 0.5172 \\
\hline $\begin{array}{c}2^{\text {nd }} \text { Design model } \\
- \text { FR3 }\end{array}$ & 1,287 & 68.7 & 0.0730 & 0.7210 \\
\hline \begin{tabular}{c}
$3^{\text {rd }} \begin{array}{c}\text { Design model } \\
- \text { Midel }\end{array}$ \\
\hline
\end{tabular} & 1,357 & 66.7 & 0.0670 & 0.4778 \\
\hline
\end{tabular}

\subsection{Structural analysis}

The structural integrity of the hermetically sealed transformer has been investigated by using the finite element method. Commercial finite element analysis S/W, ANSYS was used for the modeling and the structural analysis of the transformer.

The hermetically sealed transformer is composed of a tank and corrugated cooling fins. Since the corrugated-fin is exposed to high pressure, plastic deformation of the radiator should be considered during the analysis. In this 
study, a bilinear inelastic model was applied to simulate plastic deformation of the radiator. To define stress-strain elation curve, material properties of SS41 were applied to the analysis. Figure 4 shows the analysis results of the radiator. From the results, stress concentration is expected to occur at the center of the fins and welding point between the radiator pin and tank. Maximum deflection is expected to occur at the center of the fins.

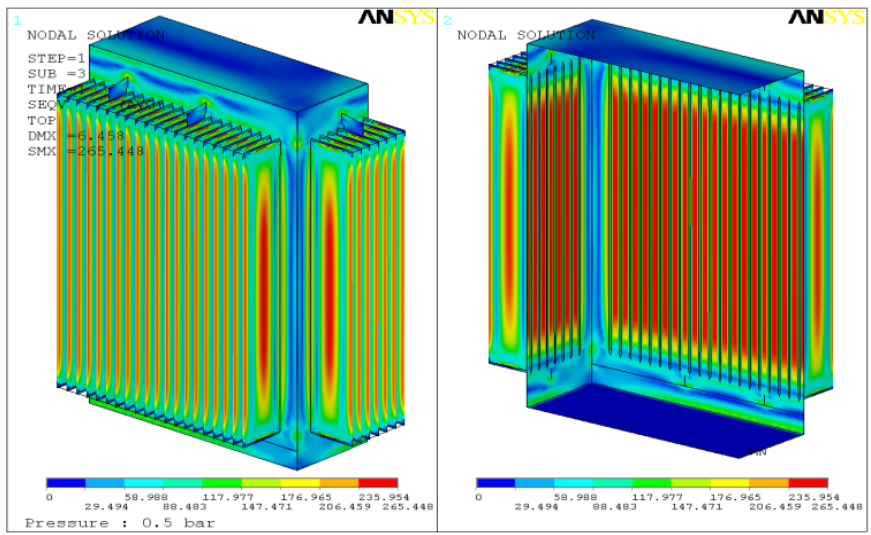

(a) Equivalent stress contour

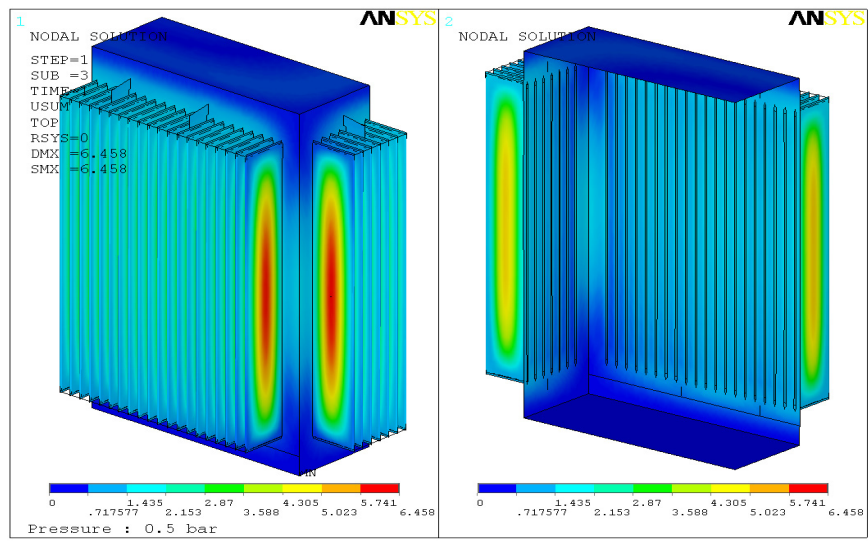

(b) Displacement contour

Figure 4: Numerical analysis results of the hermetically sealed transformer.

Structural integrity of the radiator was evaluated according to ASME Sec. VIII, Div. II, which provides general stress evaluation criteria for pressure vessels. Inner pressure of the radiator was decided from the result of the oil expansion calculation. For this study, 0.5 bar and 0.75 bar of inner pressure were applied to the transformer.

ASME code refers to evaluate the strength of pressure vessels according to the stress categories [9]. For the case of corrugated fins, high stresses occur at 
the center locations where no geometric discontinuity exists, as shown in fig. 5 . According to the stress category, therefore, strength of the fins should be evaluated with general membrane stress results. For the evaluation, membrane stresses of the fins were calculated by ANSYS post processor, as shown in fig. 5 . On the other hand, strength of the tank was evaluated with total equivalent stress result, since welding points has discontinuities and stress concentration. Figure 6 shows the occurrence of stress concentration at the welding points between the tank and the fins.

From the evaluation results, the structural integrity of the radiator was confirmed for the inner pressure of 0.5 bar. But, for the pressure of 0.75 bar, both fins and the tank of the radiator appeared to have higher than allowable stresses. Table 4 shows the stress evaluation results according to the ASME code.

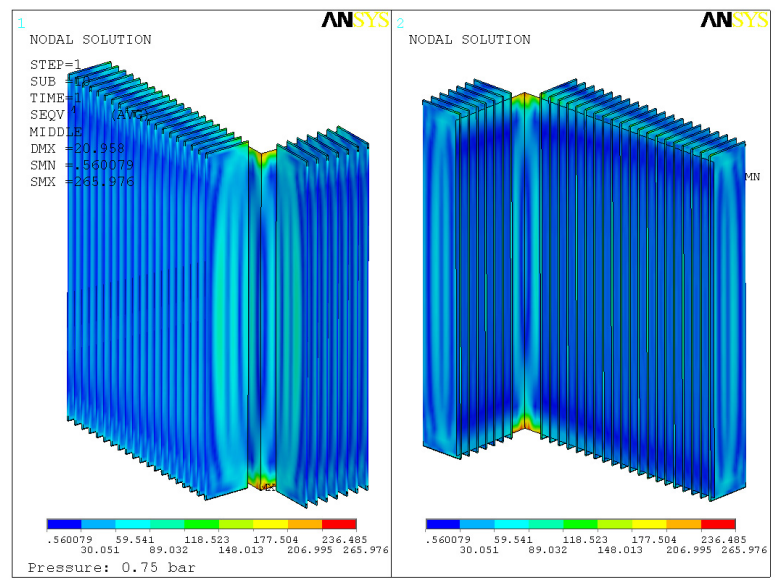

Figure 5: Membrane stress contours of the corrugated-fin.

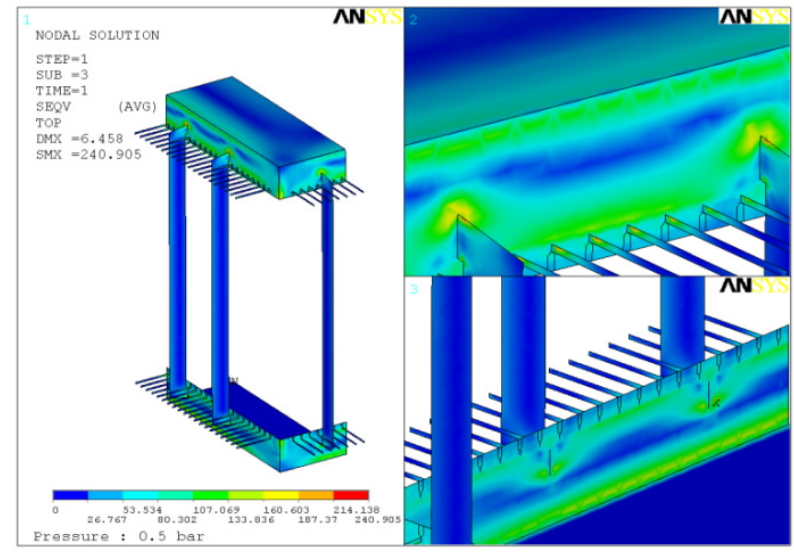

Figure 6: Total stress contour of the transformer tank. 
Table 4: $\quad$ Stress evaluation results.

\begin{tabular}{|c|c|c|c|c|c|}
\hline $\begin{array}{c}\text { Applied } \\
\text { pressure } \\
{[\text { bar] }}\end{array}$ & Evaluation part & $\begin{array}{c}\text { Max. } \\
\text { stress } \\
{[\mathrm{MPa}]}\end{array}$ & $\begin{array}{c}\text { Allowable } \\
\text { stress }^{*} \\
{[\mathrm{MPa}]}\end{array}$ & $\begin{array}{c}\text { Safety } \\
\text { factor }^{* *}\end{array}$ & Remark \\
\hline \multirow{2}{*}{0.5} & Fin & 174.9 & 220.5 & 1.26 & Safe \\
\cline { 2 - 6 } & Tank & 240.9 & 245.0 & 1.02 & Safe \\
\hline \multirow{2}{*}{0.75} & Fin & 265.9 & 220.5 & 0.83 & Failure \\
\cline { 2 - 6 } & Tank & 270.5 & 245.0 & 0.91 & Failure \\
\hline
\end{tabular}

Allowable stress for the fin $=0.9 \times$ Yield strength.

Allowable stress for the tank $=$ Yield strength.

${ }^{* *}$ Safety factor $=$ Allowable stress/Maximum stress.

\section{Experiment}

\subsection{Hydraulic test}

To confirm the numerical analysis results, a hydraulic test was conducted for the radiator. Figure 7 shows the test devices. Strain gauges were attached at 3 points of the corrugated-fin. As the inner pressure of the radiator changed, measured strain values were recorded in the data acquisition system. Figure 8 shows the location of the strain gauges attached to the radiator.

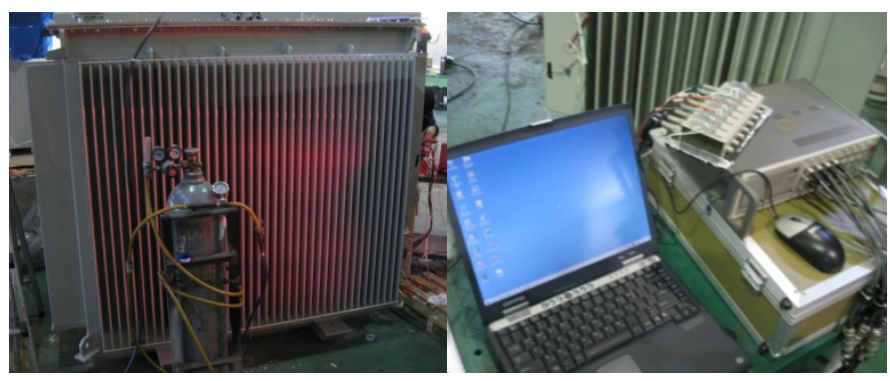

Figure 7: Hydraulic test apparatus for the hermetically sealed transformer.
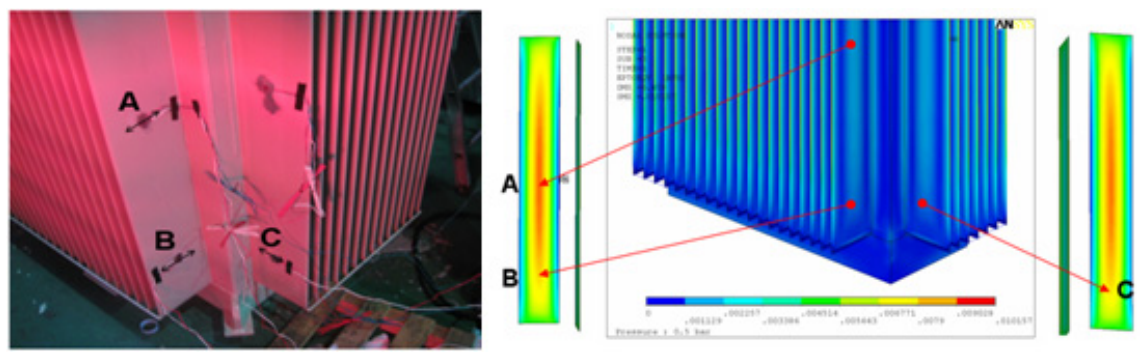

Figure 8: $\quad$ Strain measured points on the corrugated-fin. 
At the same points as the strain gauges attached locations, analysis results of strain were compared with measured values. As shown in table 5, the analysis results show good compatibility with the test results.

During the test, as the pressure of the radiator went up to 0.75 bar, large plastic deformation was observed at the center of the corrugated-fin and cracks were generated at the welding point between the corrugated-fin and the tank of the radiator. As shown in fig. 9, this phenomenon shows good agreement with the numerical analysis results. Fig. 9 shows that failures occurred during the hydraulic test at the pressure of 0.75 bar.

Table 5: $\quad$ Comparison of strain analysis results.

\begin{tabular}{|c|c|c|c|}
\hline \multirow{2}{*}{ Location } & \multicolumn{2}{|c|}{ Strain $\left(\times 10^{-5} \mathrm{~mm} / \mathrm{mm}\right)$} & \multirow{2}{*}{$\begin{array}{c}\text { Difference } \\
{[\%]}\end{array}$} \\
\cline { 2 - 3 } & Test & FEM & -1.4 \\
\hline $\mathrm{A}$ & 146 & 144 & 0.9 \\
\hline $\mathrm{B}$ & 112 & 113 & 0.0 \\
\hline $\mathrm{C}$ & 103 & 103 & \\
\hline
\end{tabular}

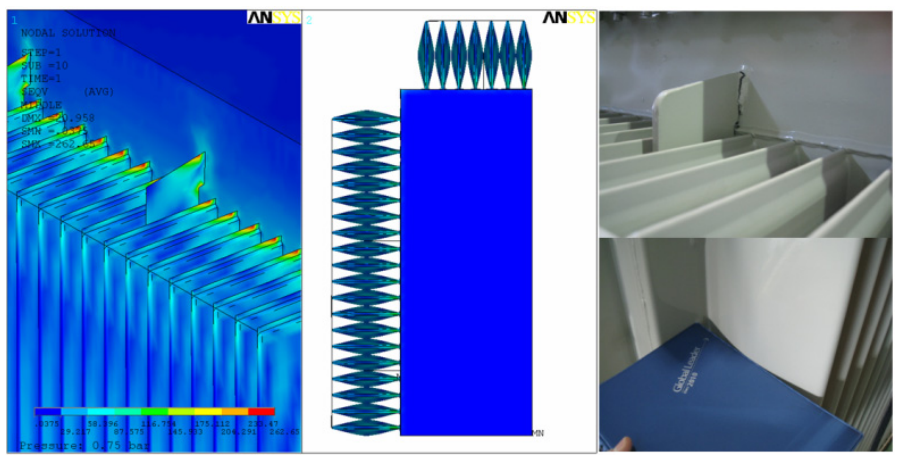

Figure 9: Configurations of mechanical failures.

\subsection{Temperature measurement}

An experiment was carried out to measure the temperature rise at the wind turbine transformer. In the experiment, the tank was filled with Midel 7131 vegetable insulation oil. A fiber optic sensor and thermal imager were used for the temperature measurement. Figure 10 shows a photo taken for the measurement of the temperature rise for a hermetically sealed transformer.

The predicted results of the temperature from numerical heat transfer analysis were compared to those of experiments. Figure 11 shows the numerical analysis results and thermal image of transformer. The prediction using the flow field analysis shows good agreement with the results of the experiment. The results of comparisons are summarized in table 6. 


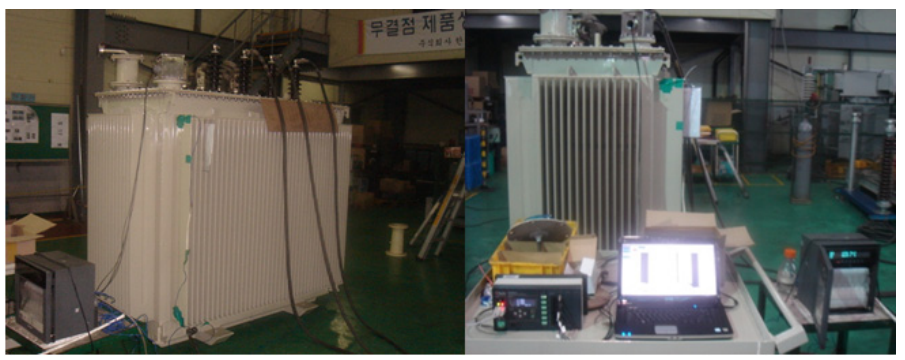

Figure 10: Experiment apparatus for a HHI wind turbine transformer.
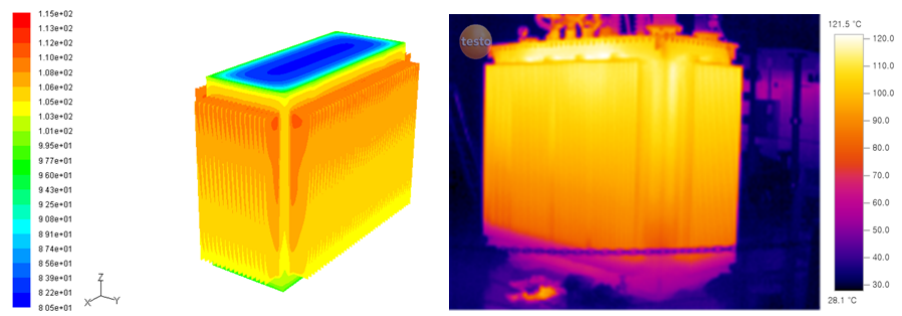

Figure 11: Experiment for a full-scale hermetically sealed oil transformer.

Table 6: $\quad$ Comparison of the numerical prediction to experimental results.

\begin{tabular}{|c|c|c|c|}
\hline \multirow{2}{*}{} & \multicolumn{2}{|c|}{ Temperature $\left[{ }^{\circ} \mathrm{C}\right]$} & \multirow{2}{*}{ ER[\%] } \\
\cline { 2 - 3 } & $\mathrm{EXP}$ & $\mathrm{CFD}$ & \\
\hline Maximum temperature & 121.5 & 125.2 & 0.57 \\
\hline Atmosphere & \multicolumn{3}{|c}{29.1} \\
\hline
\end{tabular}

CFD: Prediction from flow field analysis.

EXP: Measured temperature.

ER: Percentage difference between CFD and EXP.

\section{Conclusions}

The numerical prediction and experimental verification for the hermetically sealed vegetable oil transformer have been conducted with respect to the thermal and structural stability. The vegetable oil transformer has advantages of biodegradation and fire-resistant properties for the wind turbine transformer. However, in the case of substituting vegetable oil for mineral oil, the maximum winding temperature rises because of the decrease in internal circulation flowrate resulting from the variation of physical characteristics such as density and viscosity. For the thermal and structural stability of HHI's hermetically sealed oil transformer, the design technology of the transformer to deal with the pressure variation was investigated by fluid structure interaction simulations. The amount 
of expanded oil inside the corrugated-fin has been estimated for different load cases, and the design of the corrugated-fin to control the variations of inside oil pressure has been proposed according to the criteria from ASME BPV code. In the comparisons of the experimental and numerical results, it is found that the numerical prediction shows relatively good agreements with the experimental measurements. In conclusion, the design of the hermetically sealed transformer meets the requirements for thermal and structural integrity in the operating condition.

\section{References}

[1] Altmann, G., Hermetically sealed distribution transformers, Trafo-Union, 1977.

[2] Declercq, J. \& Schevensteen, R.V., Performance and fire behavior of stepup transformers in wind turbines. Proc. of the 2004 European Wind Energy Conference \& Exhibition, London, UK, 2004.

[3] Bertrand, Y. \& Hoang, L. C. Vegetable oils as substitute for mineral insulating oils in medium-voltage equipments. D1-202, CIGRE Session, 40, Paris, France, 2004.

[4] Tenbohlen, S., Koch, M., Vukovic, D., Weinlader, A., Baum, J., Harthun, J., Schafer, M., Barker, S., Frotscher, R., Dohnal, D. \& Dyer, P., Application of vegetable oil-based insulating fluids to hermetically sealed power transformers. A2-102, CIGRE Session, 21, Paris, France, 2008.

[5] Voukelatos, J. \& Stenborg, P., Natural ester(vegetable oil) dielectric fluid application in transformers. 04-49 Session 3-B, GCC-CIGRE-Power, 2005.

[6] Cooper Power Systems, Environtemp FR3 Fluid - Bulletin 00092 Product Information, 2001.

[7] M\&I Materials Ltd - Comparative Data Sheet Midel 7131 and Midel eN, Technical data sheet 3, 2007.

[8] Herfati D., Kamvar B.A., Tavakkol A. \& Milani K.R., Calculation of mechanical stresses in hermetically sealed transformers. Proc. of the 19th Int. Conf. On Electricity Distribution, CIRED, 2007.

[9] ASME Boiler and Pressure Vessels Code, Section VIII, Division 2, Alternative Rules, 2004 Edition with 2005 and 2006 Addenda. 